\title{
UMA INTRODUÇÃO AOS PENSAMENTOS SINGULARES SOBRE OBJETOS MATEMÁTICOS
}

\section{Pedro Carné}

\begin{abstract}
RESUMO
Apresento, neste artigo, uma introdução à possibilidade de pensarmos singularmente objetos matemáticos. Para isso, após caracterizar em linhas gerais tanto os pensamentos singulares, quanto o problema dos pensamentos singulares sobre objetos matemáticos, reconstruo duas teorias comprometidas com esta possibilidade, sejam elas as teorias de James Davies e Jody Azzouni.

Palavras-chave: Pensamentos Singulares. Objetos Matemáticos. Arquivos Mentais. Canais Informacionais.
\end{abstract}

\begin{abstract}
This paper outlines a portrayal of our capacity of thinking mathematical objects in a singular way. In order to do that, I analyze two theories that commit themselves to the truth of this capacity, be them the theories presented by James Davies and Jody Azzouni.
\end{abstract}

Keywords: Singular Thought. Mathematical Objects. Mental Files. Information Channels.

\section{Introdução}

O objetivo deste artigo consiste em apresentar uma introdução à possibilidade de pensarmos singularmente objetos matemáticos. Para isso, propõese o seguinte itinerário.

Em primeiro lugar, procura-se caracterizar os pensamentos singulares através do comportamento psico-linguístico dos termos singulares. Apesar de não ser exaustiva, esta caracterização é suficiente para delinearmos os pensamentos cujas especificações encontram-se em discussão.

Na sequência, indicamos alguns argumentos de Kent Bach contrários à existência de pensamentos singulares acerca de objetos matemáticos. Com

\footnotetext{
${ }^{1}$ Doutor em Filosofia pela PUC-RJ e professor da UACS/UFCG.

E-mail: pedrohpcarne@gmail.com. ORCID:.0000-0002-7692-8441.
} 
esta menção, pretende-se dar a conhecer, ainda que brevemente, um posicionamento contrário à possibilidade em discussão.

As duas seções seguintes apresentam argumentos favoráveis à existência de pensamentos singulares sobre objetos matemáticos. Nomeadamente, os argumentos desenvolvidos por James Davies e Jody Azzouni. A razão pela qual concentramo-nos nos argumentos destes autores consiste no fato de eles nos permitirem contemplar, em relação aos pensamentos singulares, o antagonismo entre platonismo e nominalismo em filosofia da matemática.

Por fim, faz-se o esboço de algumas questões e perspectivas suscitadas por esta pesquisa.

\section{A definição dos pensamentos singulares através do comportamento psico-semântico de seus termos}

A apresentação dos pensamentos singulares através do comportamento psico-linguístico dos termos singulares representa, talvez, a maneira mais simples de que dispomos para explicitar o contraste que esta espécie de pensamento ou maneira de pensar manifesta em relação aos pensamentos gerais ou descritivos. $^{2}$

Considere-se, por exemplo, a diferença entre os pensamentos expressados pelas sentenças "Leão Tolstói morreu em 1910" e "O autor de Guerra e Paz morreu em 1910." Os defensores da tese singularista argumentam que a primeira sentença nos autoriza a pensar em Tolstói de maneira singular, uma vez que nele pensamos por intermédio de seu nome próprio, ao passo que a segunda sentença nos faz pensar em Tolstói de maneira descritiva, na medida em que lançamos mão da descrição definida "o autor de Guerra e Paz". Isto é, a diferença entre nomes próprios e descrições definidas auxilia-nos na elaboração da diferença entre pensamentos singulares e pensamentos descritivos, pois enquanto estas fazem referência ao escritor russo de maneira indireta, através da utilização abreviada de quantificadores e propriedades, aqueles nos permitem falar de Tolstói diretamente, de maneira determinada.

${ }^{2}$ Esta estratégia manifesta-se, por exemplo, em Azzouni 2009, Jeshion 2010b e Crane 2013. 
O comportamento psico-linguístico dos pronomes demonstrativos também nos ajudam a elaborar semelhante distinção. Com efeito, os pronomes demonstrativos são capazes de nos mostrar ou de nos apresentar um determinado objeto sem nomeá-lo diretamente. Essa capacidade é caracterizada como função deíctica e constitui, de acordo com algumas análises gramaticais, o traço definidor dessa classe de pronomes (CUNHA e CINTRA, 2008, p. 342-356). Isto significa que o mero emprego de um pronome demonstrativo é suficiente para situarmo-nos em relação a um certo objeto. Assim, ao encontrarmo-nos diante de uma garrafa laranja em cima da mesa, tanto podemos pensar que há um objeto que instancia a propriedade de ser garrafa, ser laranja e encontrar-se em cima da mesa (acrescendo-se que somente um objeto instancia todas essas propriedades conjuntamente), quanto pensar que o fato de esta garrafa laranja encontrar-se em cima da mesa origina uma sentença tal como "esta garrafa laranja em cima da mesa".

De todo modo, os pensamentos singulares são usualmente caracterizados como pensamentos não-descritivos, os quais, naturalmente, contrapõem-se aos pensamentos descritivos. Em outras palavras, os pensamentos singulares constituem uma espécie de pensamento ou uma maneira de pensar por intermédio da qual nós nos relacionamos com um determinado objeto sem o auxílio de uma conceitualização geral ou descritiva do mesmo.

\section{Por que não poderíamos pensar singularmente os objetos matemáticos?}

É inegável que possuímos pensamentos singulares sobre os mais variados objetos do mundo, afirma Kent Bach. Se assim não os pensássemos, continua, nunca nos relacionaríamos com nenhum objeto específico em nosso pensamento: nossa visão do mundo seria inteiramente qualitativa $(\mathrm{Cf}$. $\mathrm{BACH}$, 2010, p. 39). Naturalmente, deve ser motivo de atenciosa investigação de que modo somos capazes de pensar singularmente um determinado objeto.

A melhor maneira de apreciarmos o problema dos pensamentos singulares, para Bach, é relacioná-lo com um problema que lhe seria análogo, seja este o problema da particularidade de um objeto na percepção. Suponhamos, por exemplo, que você esteja lendo este artigo em seu celular. Provavelmente, 
você está vendo o seu celular na sua frente. Apesar disso, diz-nos Bach, diversos filósofos acreditam na possibilidade de você possuir a mesma experiência que possui agora (no momento em que olha para o seu celular) ainda que fosse outro o celular que estivesse na sua frente, ainda que fosse outro o objeto, ou ainda que nada estivesse na sua frente, como se a presença do objeto não fosse essencial para a constituição da experiência subjetiva do mesmo. A conclusão extraída destes cenários por tais filósofos é a de que "o conteúdo de todas as experiências perceptuais apenas podem ser gerais” (ibid., p. 40). Efetivamente, os argumentos de Bach caminham na contramão de tais diagnósticos.

Bach afirma que, "certamente, quando percebemos algo, estamos conscientes disso, e não apenas de que existe uma coisa única de um certo tipo" (idem). Nossa experiência de um objeto concreto, continua, não seria semelhante à visão de uma sombra ou de uma pegada. Tampouco seria semelhante à visão da mancha de caneta em uma camisa. Nestes casos, nossa relação com o objeto responsável pela sombra ou pela pegada, assim como com a caneta cuja tinta manchou a camisa, só se processaria com o auxílio de descrições. Como, porém, poderíamos explicar nossa relação com um objeto independentemente de uma descrição? Isto é, o que haveria na experiência de um objeto que demandaria a presença deste objeto específico, e não a presença de quaisquer outros objetos possuidores de características idênticas? Em linhas gerais, Bach defende que é suficiente, para pensarmos singularmente um determinado objeto, estarmos conectados com alguma representação do mesmo, uma vez que tais representações funcionariam como "indexicais mentais". E afirma: "existem diferentes tipos de relações representacionais de re, baseadas na percepção, memória ou comunicação; porém, por mais remotas e conectadas que sejam, [estas relações] devem estar fundamentadas na percepção do objeto representado por parte de algum indivíduo" (ibid., p. 61).

A simples associação do problema dos pensamentos singulares ao problema (análogo) da particularidade na percepção permite-nos assinalar um traço fundamental dos pensamentos singulares para Bach: seu caráter causal. O caráter causal dos pensamentos singulares implicaria por sua vez na tese se- 
gundo a qual só pensamos desta maneira objetos cuja percepção ocorreu em algum momento de nossa existência (caso não tenhamos percebido o objeto em questão, é fundamental que o mesmo tenha sido percebido por outra pessoa). E, com o perdão da brevidade, se prosseguirmos neste raciocínio, e reconhecermos que os objetos matemáticos são objetos abstratos, concluiremos a impossibilidade de pensarmos singularmente objetos matemáticos. De fato, nas palavras de Bach (1987, p. 12), "a relação que faz de algo um objeto de pensamento de re é uma relação causal [...]. Entidades abstratas simplesmente não podem entrar em relações causais". ${ }^{3}$

Este não é o espaço para investigarmos pormenorizadamente a teoria de Bach. Para nossos propósitos, é suficiente ressaltarmos que, em sua concepção, um traço fundamental dos pensamentos singulares é o seu caráter causal. Particularmente, o apelo à percepção é suficiente para compreendermos a interdição a qualquer tratamento aos objetos abstratos. Embora Bach reconheça o fato de sua teoria ter sido elaborada com a intenção de explicar nossos pensamentos singulares acerca de objetos concretos (ainda que, em sua opinião, tais objetos não constituam a totalidade dos objetos que poderíamos pensar singularmente), ela se tornou uma espécie de paradigma da impossibilidade de pensarmos singularmente os objetos abstratos. Naturalmente, isso não impediu que muitos esforços fossem feitos para contradizer seus argumentos.

\section{Pensamentos singulares sobre objetos matemáticos: o poder explicativo dos arquivos mentais}

Nesse sentido, o primeiro ponto de vista favorável aos pensamentos singulares sobre objetos matemáticos que gostaria de explorar encontra-se em um recente artigo publicado por James Davies. Nele, Davies argumenta que nenhuma das três principais teorias contemporâneas sobre a singularidade de nossos pensamentos — teoria da acquaintance, instrumentalismo semântico e

\footnotetext{
${ }^{3}$ Posteriormente, Bach justifica sua decisão de não elaborar em maiores detalhes, ainda que negativamente, nossa impossibilidade de pensar singularmente objetos abstratos: "não discuti a referência a entidades abstratas porque acredito que os problemas reais não se encontram na relação de referência, mas no estatuto ontológico e epistemológico destas entidades" (1987, p. 261).
} 
cognitivismo semântico - é capaz de explicar satisfatoriamente a razão pela qual estaríamos aptos a pensar os objetos matemáticos de maneira singular. ${ }^{4}$ Em sua opinião, se estamos de fato interessados em compreender de que forma poderíamos assim pensar tais objetos, deveríamos examinar minuciosamente alguns aspectos da teoria dos arquivos mentais, especificamente as condições para desenvolver e manter um arquivo mental sobre um objeto percebido no passado, uma vez que tais condições auxiliariam na compreensão do caso dos objetos matemáticos.

As teorizações sobre a referência e o pensamento singulares deveriam respeitar, o máximo possível, nossas intuições mais comuns e habituais sobre o comportamento psico-semântico dos termos com os quais desenvolvemos tais pensamentos, de acordo com Davies. Assim, na medida em que nossa intuição tende a considerar o termo com o qual designamos um objeto matemático como um termo singular, ao invés de considerá-lo como uma descrição definida (seja disfarçada, seja abreviada), Davies afirma (2019, p. 4) que "deveríamos procurar uma explicação que permita [que os termos numéricos] funcionem como termos singulares — pelo menos até que seja mostrado que não existe uma explicação plausível”. Não é bem essa a direção de seu artigo, no entanto. Ao invés de elaborar o funcionamento dos termos numéricos como termos singulares, o artigo de Davies, por um lado, defende a existência de pensamentos singulares sobre objetos matemáticos baseado em nossas intuições sobre o comportamento psico-semântico dos termos numéricos, e, por outro lado, exibe de que forma tais pensamentos seriam possíveis com o auxílio da teoria dos arquivos mentais.

Uma vez que Davies concentra seus maiores esforços na especificação da maneira através da qual a teoria dos arquivos mentais viabilizaria os pensa-

\footnotetext{
${ }^{4}$ Ao subscrever semelhante julgamento - de que a teoria da acquaintance, o instrumentalismo e o cognitivismo semânticos seriam as principais teorias contemporâneas sobre a natureza de nossos pensamentos singulares —, Davies tão somente repercute a configuração teórica esboçada por Robin Jeshion em vários de seus trabalhos. Desta forma, se quisermos entender os fundamentos desta configuração, devemos buscar um maior esclarecimento nos trabalhos de Jeshion. Contudo, para não nos alongarmos nas questões preliminares, remetemos o leitor para o artigo de Jeshion intitulado "Pensamento Singular: Acquaintance, Instrumentalismo Semântico e Cognitivismo" (2010c), no qual, por um lado, são entrelaçadas suas críticas ao caráter extremamente restritivo do conceito de acquaintance e à liberalidade excessiva do instrumentalismo semântico, e, por outro lado, sua teoria da autoridade cognitiva é apresentada de maneira mais detalhada.
} 
mentos singulares sobre objetos matemáticos, vejamos alguns aspectos desta teoria.

Os arquivos mentais são costumeiramente definidos como uma espécie de depósito mental de informações que julgamos serem sobre um determinado objeto (ainda que as condições sob as quais um arquivo mental efetivamente se refira a um objeto varie de teoria para teoria), e sua relação com nossos pensamentos seria, por assim dizer, constitutiva. Isto é, pensamos em um objeto (seja de maneira singular, seja de maneira descritiva) se e somente se, no processo de pensamento, ativamos ou utilizamos um arquivo mental singular que se lhe refira. $\mathrm{O}$ fato de existirem tanto arquivos mentais singulares, quanto arquivos mentais descritivos torna perceptível que Davies simplesmente traduz em termos de arquivos mentais a diferença entre pensamentos singulares e descritivos, sem avançar seja na especificação de ambas as maneiras de pensar, seja na especificação da natureza destes "arquivos mentais", seja na especificação do significado desta "ativação" dos arquivos mentais no processo de pensamento. Com efeito, após traduzir a diferença entre pensamentos singulares e descritivos em termos de arquivos mentais, a estratégia argumentativa adotada por Davies apresenta-nos uma subdivisão de cada um destes ramos. Isto é, os arquivos mentais singulares podem ser demonstrativos ou estáveis, ao passo que os arquivos mentais descritivos podem ser puros ou holísticos.

É forçoso traçar o seguinte parêntese: na complexa engenharia conceitual posta em movimento para dar conta do caso dos pensamentos singulares sobre objetos matemáticos, devemos inserir três teses subscritas (não necessariamente fundamentadas) por Davies: (i) que um arquivo mental "vazio" é desprovido de referência; (ii) que o mero surgimento de um arquivo mental em nossa cognição implica a possibilidade de o ativarmos ou utilizarmos conscientemente; e (iii) que a identidade de um arquivo mental é transparente para o indivíduo que o utiliza (sabemos se um arquivo mental é igual ou diferente em relação a outro). ${ }^{5}$

\footnotetext{
${ }^{5}$ A fundamentação da transparência de um arquivo mental, no texto de Davies, decorreria da "chancela" de Recanati a um comentário introdutório de Laura Schroeter no artigo "A ilusão da transparência", de acordo com o qual "a maioria dos filósofos da mente aceita a tese $[\ldots]$ de que possuiríamos um acesso transparente ao conteúdo de nossos pensamentos: da-
} 
Pois bem, a diferença entre os dois tipos de arquivos mentais singulares, para Davies, é genética, ou seja, manifesta-se na origem da informação por eles armazenada. Como os arquivos mentais baseiam-se em certas relações que estabelecemos com os objetos no ambiente, sejam elas relações epistemicamente recompensadoras (por permitir-nos obter informações diretamente a partir do objeto), os arquivos mentais demonstrativos seriam aqueles que existem durante a relação perceptual com o objeto, isto é, eles existem enquanto se mantém a relação que possibilita o fluxo de informação do objeto para o arquivo. Já os arquivos mentais estáveis, naturalmente, não necessitariam da manutenção de nenhuma relação perceptual com o objeto para se manterem em nossa cognição.

Desta distinção entre arquivos mentais demonstrativos e estáveis, Davies conclui o que nos parece uma obviedade: quando pensamos singularmente um objeto por intermédio de um arquivo mental estável, isso significa que não necessariamente o estamos percebendo no momento presente. Isto é, como o arquivo mental é estável, podemos não nos encontrar em uma relação perceptual com o objeto de nosso pensamento - o caso mais emblemático dessa situação seriam os objetos percebidos no passado. Esta possibilidade é explicada através de uma "conversão" sofrida por um arquivo mental demonstrativo por intermédio da qual ele se metamorfosearia em um arquivo mental estável. Como nem todos os arquivos mentais demonstrativos convertem-se em arquivos mentais estáveis, Davies procura especificar o papel desempenhado pela "retenção de informação" que possibilitaria esta conversão, por acredo que sejamos minimamente racionais, não podemos simplesmente confundir um conteúdo conceitual por outro" (SCHROETER, 2007, p. 597). Desta afirmação, Davies conclui sumariamente que, "se isto está correto, então, se parece ao indivíduo que ele está reativando o mesmo arquivo mental uma segunda vez, é isso que ele está fazendo. Consequentemente, a identidade do arquivo mental é transparente ao indivíduo" (DAVIES, 2019, p. 21). No entanto, deve-se registrar que o comentário de Schroeter, na íntegra, é o seguinte: "O senso comum nos diz que normalmente possuímos um acesso direto e confiável aos conteúdos de nossos pensamentos conscientes. Mas a maioria dos filósofos da mente aceita a tese bem mais forte de que possuiríamos um acesso transparente ao conteúdo de nossos pensamentos: dado que sejamos minimamente racionais, não podemos simplesmente confundir um conteúdo conceitual por outro" (SCHROETER, 2007, p. 597). Para ela, aliás, nada tão forte quanto a "transparência" é defendido pela psicologia contemporânea. Mesmo Recanati não admite em termos absolutos a transparência de um arquivo mental para um indivíduo, haja vista as análises apresentadas em "Transparência e os seus limites" e em "Factividade, trans parência e Fraca co-referência de jure" (respectivamente RECANATI, 2012, p. 133-143; e RECANATI, 2016, p. 14-31). Sem apelar para uma concepção irrestrita da "transparência", todavia, a análise de Davies se enfraqueceria substancialmente. 
ditar que aí encontrará a chave para desembaraçar o caso dos pensamentos singulares sobre objetos matemáticos. Sua especificação se traduzirá em duas teses.

A primeira refere-se ao fato de a retenção de informação ser uma condição necessária e suficiente para a conversão de um arquivo mental demonstrativo em um arquivo mental estável. Sua necessidade decorre de uma tese derivada da própria definição dos arquivos mentais, a de que um arquivo mental "vazio" não possuiria nenhuma referência. Se um arquivo mental vazio não possui referência, conclui Davies, a falha na retenção de informação sobre um objeto resulta na ausência de um arquivo mental que se lhe refira. E a suficiência? Para Davies (ibid., p. 14), "reter informação que assumimos ser sobre um objeto individual é apenas reter um arquivo mental. Assim, se um sujeito retém informação sobre um objeto na ausência de uma ligação perceptual, então ele está mantendo um arquivo mental estável para este objeto". Ou seja, Davies está nos dizendo que a conversão de um arquivo mental demonstrativo em um arquivo mental estável decorre simplesmente do fato de que, por um lado, retemos informação sobre um objeto qualquer, e, por outro lado, se retemos informação sobre ele é porque há um objeto cujas informações retidas justificaria a existência do arquivo mental.

A segunda tese refere-se a uma possibilidade mais ousada. Davies pensa que não apenas os arquivos mentais demonstrativos podem ser convertidos em arquivos mentais estáveis, mas que haveriam arquivos mentais descritivos que também poderiam ser convertidos em arquivos mentais estáveis, tornando possível, a uma descrição, auxiliar no desenvolvimento de pensamentos singulares. De acordo com Davies (ibid., p. 16), o resultado desta conversão de arquivos mentais descritivos seria "um arquivo mental estável sobre o objeto que satisfaz a descrição no momento da conversão - assim como o referente de um arquivo mental estável derivado de uma percepção é o referente de um arquivo mental demonstrativo convertido no momento da conversão". Pois bem, como essa conversão de um arquivo mental descritivo em um arquivo mental estável ocorreria? 
Para Davies, é fundamental que, em primeiro lugar, concebamos uma descrição definida satisfeita por apenas um objeto. A partir desta descrição, e, talvez, de algumas outras crenças que possuímos acerca deste objeto, inferimos algumas informações sobre o objeto descrito, informações que, por alguma razão, retemos em nossa mente. Davies, então, afirma:

Dado que o sujeito está retendo um estoque de informações sobre o objeto, sua cognição converte a descrição definida em um arquivo mental estável que se refere ao objeto que satisfaz semelhante descrição. E assim, dado que a posse de um arquivo mental estável que se refere a um objeto é necessária para tornar alguém capaz de possuir pensamentos singulares sobre o mesmo, o sujeito está agora a meio caminho de possuir pensamentos singulares sobre o objeto que satisfaz a descrição (ibid., p. 17).

O cenário desenhado por Davies é animador. Todavia, há nele algumas lacunas teóricas. Afinal, Davies investigava uma subdivisão dos arquivos mentais em demonstrativos e estáveis e explicava-nos de que maneira ocorreria a conversão de um (o demonstrativo) em outro (o estável) quando lançou um novo problema para sua proposta, seja ele uma nova conversão, isto é, a conversão de um arquivo mental descritivo em um arquivo mental (singular) estável. E isso, devemos acrescentar, sem especificar de qual arquivo mental descritivo estamos falando.

Como anteriormente indicado, os arquivos mentais descritivos podem ser puros ou holísticos. Um arquivo mental puramente descritivo exibiria especificamente uma descrição definida sobre o objeto em questão, de modo que qualquer mudança na configuração desta descrição alteraria substancialmente o arquivo mental. Em outras palavras, qualquer mudança na descrição acarretaria o fim de um arquivo mental puramente descritivo bem como o início de outro. Por outro lado, um arquivo mental holisticamente descritivo apresentaria em sua constituição um conjunto de descrições para a identificação de um objeto, de modo que ele sobreviveria a uma mudança no estilo "navio de Teseu" - no sentido em que este arquivo sobreviveria a modificações paulatinas em suas descrições constituintes. Dito de outra forma, um arquivo mental holisticamente descritivo não sobreviveria a uma mudança radical de todas as suas descrições de uma só vez, mas permaneceria estruturalmente 
inalterado em função de pequenas substituições de seus elementos. ${ }^{6}$ Mas qual a diferença entre um arquivo mental singular e um arquivo mental descritivo, afinal?

Davies distingue um arquivo mental singular de um arquivo mental descritivo em função dos critérios que regeriam sua permanência em nossa cognição. Mais especificamente, a distinção entre ambas as espécies de arquivos é traçada por intermédio de uma análise do processo de modificação nas informações neles armazenadas. Para Davies, enquanto os arquivos mentais singulares seriam fortemente expressivos, em função da origem de sua informação (uma relação direta com o objeto), os arquivos mentais descritivos seriam menos expressivos, pois sua conexão com o objeto dependeria de uma única informação indireta: a relação de satisfação da descrição a partir da qual o arquivo se originou. Um arquivo mental descritivo não sobreviveria, em princípio, a uma mudança nesta descrição (ou permaneceria em um constante processo de empalidecimento, no caso dos arquivos mentais holisticamente descritivos).

Pois bem, apesar das muitas lacunas, o cenário no qual o estudo de Davies se movimenta é constituído pelas seguintes teses: (i) dependemos de arquivos mentais singulares (demonstrativos ou estáveis) para pensar de maneira singular um determinado objeto; (ii) o conteúdo dos arquivos mentais é transparente para o indivíduo que o utiliza (o indivíduo sabe se está utilizando um arquivo mental em dois momentos diferentes ou se está utilizando dois arquivos mentais distintos); (iii) um arquivo mental singular demonstrativo converte-se em um arquivo mental singular estável por intermédio de uma retenção de informação (cujas condições de possibilidade não foram pormenorizadas); (iv) uma descrição definida, que intuitivamente originaria um arquivo mental (puramente ou holisticamente) descritivo pode ser convertida em um arquivo mental singular estável. Com este instrumental teórico, vejamos a situação imaginada por Davies para dar sentido à sua proposta.

Imagine uma comunidade matemática para a qual a melhor descrição dos números naturais dá-se através dos axiomas Dedekind-Peano, de acordo

\footnotetext{
${ }^{6}$ Rachel Goodman (2016) elabora uma discussão mais detalhada desta caracterização dos arquivos mentais descritivos.
} 
com os quais o número 0 seria o único número que não seria o sucessor de outro número, o número 1 seria o sucessor de 0 , o 2 o sucessor do 1 e assim por diante. Subitamente, esta comunidade passa a acreditar que os números seriam melhor descritos pelas definições de Frege-Russell, isto é, que o número 0 seria o conjunto dos conjuntos equinuméricos ao conjunto de objetos não-idênticos a si mesmos, o número 1 seria o conjunto de todos os conjuntos equinuméricos à 0 , o número 2 seria o conjunto de todos os conjuntos equinuméricos à 0 ou equinuméricos à 1 etc. Esta crença, adverte-nos Davies, não é o resultado de uma inferência feita a partir dos axiomas Dedekind-Peano: ela pode ter se originado de avanços ou desenvolvimentos da teoria dos conjuntos aliados a uma parcimônia ontológica. Até aí, pas de probleme. Davies então acrescenta a este cenário a seguinte informação (ibid., p. 20): "após esta mudança, parece subjetivamente aos membros desta comunidade que, quando eles pensavam e falavam sobre os números naturais, eles realmente estavam falando e pensando sobre conjuntos de conjuntos equinuméricos a todo momento, à despeito das aparências em contrário”.

Com isto em mente, Davies pede que imaginemos um indivíduo específico que pertença a esta comunidade. Isto é, um indivíduo que, em primeiro momento, admite os axiomas Dedekind-Peano, e, em um segundo momento, reconhece a verdade das definições de Frege-Russell. Por conseguinte, o arquivo mental deste indivíduo para o número 0 apresentaria, em um primeiro momento, informações como "é o único número que não é o sucessor de nenhum outro número", e, em um segundo momento, informações como "é o conjunto dos conjuntos equinuméricos a $\{y: y \neq y\}$ ”. Davies acrescenta que, se parece subjetivamente a este indivíduo que seus pensamentos sempre se pautaram pelas definições Frege-Russell, isto significa que seus pensamentos, antes e depois da mudança paradigmática, partilhariam do mesmo conteúdo (deve-se recordar que, para Davies, em um sentido estrito de conteúdo, para que dois pensamentos expressem o mesmo conteúdo, seus arquivos mentais devem ser idênticos). Agora, sim, estamos diante de um sério dilema: como é possível que pareça subjetivamente a um indivíduo que seu arquivo mental permanece o mesmo, ainda que tenha sofrido semelhante transformação em 
seu conteúdo? No caso, estamos falando de um arquivo mental cuja referência é um número que, em um primeiro momento, era caracterizado com o auxílio dos axiomas de Dedekind-Peano, e, em um segundo momento, passa a ser caracterizado com as definições Frege-Russell.

Davies avalia que, se a descrição definida que caracteriza um número específico originar um arquivo mental (pura ou holisticamente) descritivo, não poderia parecer subjetivamente ao indivíduo que utiliza este arquivo que, nos dois momentos diferentes, este arquivo possuiria o mesmo conteúdo. Pois, se um arquivo mental descritivo não sobrevive a uma mudança na descrição que o originou, não poderia parecer subjetivamente ao indivíduo que ele está ativando o mesmo arquivo mental em dois momentos distintos, uma vez que a transparência dos arquivos mentais exibiria o fim de um arquivo (baseado nos axiomas Dedekind-Peano) e o início de outro (baseado nas definições FregeRussell). Deste modo, se a identidade do arquivo mental é transparente para o indivíduo, e se parece subjetivamente ao indivíduo que o conteúdo de seu arquivo mental é o mesmo antes e depois da mudança (dos axiomas DedekindPeano para as definições Frege-Russell), este indivíduo está ativando o mesmo arquivo mental em duas ocasiões distintas, e este arquivo mental não pode ser descritivo (ou, pelo menos, não pode ser puramente descritivo). Porém, por qual razão poderia parecer subjetivamente a um indivíduo que um arquivo mental possuiria o mesmo conteúdo antes e depois de a definição de número ter se modificado? Afinal, no exemplo de Davies, a modificação do conteúdo do arquivo é um fato e a percepção subjetiva do indivíduo ainda está por se justificar.

Aqui, Davies recorre a uma confusa validação para sua tese, pois afirma (ibid., p. 22) que "uma razão para pensarmos que pode [parecer subjetivamente ao sujeito que ele está utilizando o mesmo arquivo mental] é que não temos de procurar muito longe para ver filósofos e matemáticos sustentando afirmações que, em sua leitura mais óbvia, implica que esta aparência é possível”. Nesta direção, não seria incorreto identificar o coração da análise de Davies com a afirmação inaugural de Azriel Levy em seu livro Basic Set Theory (1979, p. 3, meus grifos), segundo a qual "todos os ramos da matemática são 
desenvolvidos, consciente ou inconscientemente, em teoria dos conjuntos". Davies interpreta esta afirmação de Levy não apenas como uma anuência, mas como uma corroboração da possibilidade de um indivíduo preservar o mesmo arquivo mental para um objeto matemático independentemente de quaisquer reconceitualizações sofrida por tal objeto.

Em suma, Davies afirma que duas teses viabilizariam a possibilidade de desenvolvermos pensamentos singulares sobre objetos matemáticos abstratos:

Primeiro, que para possuir tais pensamentos é necessário que nós tenhamos arquivos mentais estáveis para tais objetos. Argumentei que isso não requer nada mais do que possuir pensamentos singulares baseados na memória. Segundo, para estes arquivos mentais estáveis serem dispositivos de pensamento singular requer que eles sejam capazes de sobreviver simultaneamente a uma completa mudança nas descrições que fixam sua referência; algo que é intuitivamente possível (op. cit., p. 23).

Apesar das lacunas teórico-conceituais do argumento de Davies, bem como de sua tácita aceitação de um "essencialismo oculto" naquilo que se refere aos objetos matemáticos, sua análise incorpora dois fortes pressupostos para defender a existência de pensamentos singulares sobre objetos matemáticos: por um lado, a distinção entre pensamentos singulares e descritivos em termos do conteúdo de pensamento; por outro lado, o fato de que os pensamentos singulares dependem dos objetos pensados para se sustentar.

\section{Pensamentos direcionados para objetos sobre (inexistentes) objetos matemáticos}

Não seria exagerado afirmar que Azzouni rejeita em sua análise cada um dos pressupostos assumidos por Davies. Isto é, para Azzouni, nem os pensamentos singulares serão caracterizados em termos de seu conteúdo, nem serão dependentes do objeto, e muito menos encontrarão seu fundamento na teoria dos arquivos mentais. A possibilidade de pensarmos singularmente um objeto matemático — tal como um número natural — será por ele expressada nos seguintes termos (2011, p. 60): "o mero uso de um nome-numérico em domínio público é suficiente para ativar pensamentos direcionados para obje- 
tos mesmo sem um (genuíno) canal informacional". Vejamos, então, os elementos movimentados por Azzouni na elaboração desta sua proposta.

A maneira mais frutífera para estudarmos o fenômeno da singularidade em nossos pensamentos consistiria no exame atento do papel cognitivo por eles desempenhado, julga Azzouni. Isto significa reconhecer um divórcio entre a "referência" e a "atinência" de nossos pensamentos, uma vez que "referência é, por definição, uma relação com um objeto existente; [ao passo que] atinência é a mera representação de alguma coisa no pensamento, ela existindo ou não" (CRANE, 2011, p. 23). Consequentemente, para pensarmos singularmente, precisaríamos possuir, em primeiro lugar, alguma coisa em mente.

A perspectiva cognitiva permite a Azzouni afirmar que os pensamentos singulares não precisam ser somente sobre objetos existentes, como pretendera, por exemplo, John McDowell (que define um pensamento singular como aquele que não seria possível caso o objeto pensado não existisse) (Cf. 1998, p. 204). Em seus termos (AZZOUNI, 2011, p. 46), "quando penso "Mickey Mouse foi inventado por Walt Disney", estou pensando em algo específico (Mickey Mouse); estou pensando nele exatamente da mesma maneira que estou pensando no específico Walt Disney. E posso fazer isso apesar de meu total conhecimento de que Mickey Mouse não existe em sentido algum”.

É importante ressaltar que, ao estudar os pensamentos singulares com ênfase em seu comportamento cognitivo, Azzouni afasta completamente duas teses defendidas por Davies, a de que tais pensamentos dependem do objeto e a de que ele seriam melhor caracterizados em termos de seu conteúdo. Isto é, a justificativa para o fato de nossos pensamentos singulares não serem caracterizados em termos de seu conteúdo caminha de braços dados com a razão pela qual tais pensamentos não seriam dependentes da existência do objeto. Fundamentalmente, para Azzouni, o que define um pensamento singular é a maneira como pensamos e não o conteúdo pensado. Os pensamentos singulares seriam especificados por intermédio de uma aguda observação de seus traços psíquicos, de seu caráter episódico, e não através de seu conteúdo proposicional. Em função disso, eles seriam melhor caracterizados como “pensamentos direcionados para objetos", pois, assim como podemos pensar 
singularmente um objeto singular, também poderíamos pensar "singularmente" uma pluralidade de objetos. Aliás, o fato de podermos pensar pluralidades de maneira singular constrói a ponte teórica que possibilitará a rejeição dos arquivos mentais como o fundamento psíquico de tal maneira de pensar.

Um breve parêntese faz-se necessário: penso que qualquer apreciação da relação entre os arquivos mentais e os pensamentos singulares tangencia as reflexões de François Recanati, um dos maiores defensores contemporâneos da metáfora dos arquivos mentais. Em artigo recente (2014, p. 165), porém, Recanati adverte que "um número crescente de filósofos tem utilizado a metáfora dos arquivos mentais para iluminar os pensamentos singulares. Pessoas diferentes, porém, elaboram a metáfora diferentemente". Esta advertência é fundamental para a apreciação da crítica de Azzouni aos arquivos mentais, pois tais críticas são endereçadas à elaboração desta metáfora por Tim Crane.

De maneira resumida, duas características diferenciam os arquivos mentais gerais e singulares, no entender de Crane. Por um lado, a maneira como o sujeito concebe a aplicação da informação armazenada no arquivo — isto é, o que tornaria geral um determinado arquivo seria o fato de o sujeito compreender uma de suas informações como sendo verdadeira quando aplicada a muitos objetos, e, inversamente, o que tornaria singular um arquivo seria o fato de o sujeito não compreender uma informação nele contida como aplicando-se a muitos objetos. Por outro lado, a maneira como uma determinada informação sobre um objeto passa a ser armazenada no arquivo — ou seja, enquanto as informações nos arquivos mentais singulares seriam passíveis de revisão, pelo menos uma informação em um arquivo mental geral seria essencial para a estruturação do mesmo. Com efeito, Azzouni questionará ambas as características.

A primeira crítica de Azzouni à elaboração de Crane consiste no fato de podermos pensar pluralidades de maneira singular. Afinal, isto embaralharia a primeira das duas características. Se podemos pensar pluralidades de maneira singular, ou, nos termos de Azzouni, se podemos desenvolver pensamentos direcionados a pluralidades de objetos, então somos capazes de compreender uma informação em um arquivo mental singular como fazendo 
sentido quando aplicada a muitos objetos. Azzouni oferece como exemplos os casos de "Bourbaki" e da "família Gaona". Sobre o primeiro, ele afirma (2011, p. 49): "meu arquivo "Bourbaki" contém o fato de que houve vários deles ao longo do tempo, que nenhum deles era americano e algumas outras coisas pouco informativas (e, provavelmente, informações equivocadas também)". Já sobre o segundo (idem): "sou quase inteiramente ignorante dos detalhes acerca dos membros individuais desta trupe. Não tenho dúvidas, porém, de que minha sentença anterior corresponde a um pensamento direcionado para um objeto sobre eles, mesmo que eu sequer saiba quantos eles são”. Esta crítica, no entanto, apenas tangencia o verdadeiro problema dos arquivos mentais.

Azzouni pensa que a metáfora dos arquivos mentais oferece uma explicação superficial para a diferença entre os pensamentos direcionados para objetos e os pensamentos descritivos. Para isso, ele supõe que a diferença entre ambas as maneiras de pensar se dá tal como pensa Crane, isto é, através da maneira como novas informações associadas com o objeto de nosso pensamento é organizada no arquivo. Assim, "quando um arquivo mental é direcionado para um objeto, qualquer uma das descrições no arquivo parece passível de revisão. [...] Quando, porém, o arquivo é descritivo, certas descrições são tomadas como essenciais para o arquivo, e qualquer referência que utilize tal arquivo deve ser mediada por esta descrição" (ibid., p. 52). Este quadro significa que, por exemplo, ao pensarmos singularmente sobre "Bourbaki", mesmo que venhamos a descobrir que este nome não se refere a uma pessoa específica, ainda podemos pensar sobre ele por intermédio de um arquivo mental singular.

Em contrapartida, no caso dos arquivos mentais descritivos, independentemente do que venhamos a descobrir sobre o objeto de nosso pensamento, a descrição essencial para a estruturação do arquivo nele permaneceria. $\mathrm{O}$ problema é que, "no pensamento, nós marcamos intuitivamente as diferenças entre os casos nos quais o insucesso da descrição definida faz com que não saibamos se algo está sendo pensado ou não; concomitantemente, se a descrição é passível de revisão ou não" (idem). Isto é, continua Azzouni, "ainda que 
um indivíduo use um nome, nós podemos compreender uma diferença genuína em seu pensamento entre pensar com um nome através de uma descrição, e não pensar assim" (idem). E arremata:

A possibilidade de revisão da descrição associada ao pensamento de um objeto ser o critério para saber se este pensamento é descritivo ou não faz com que o teste intuitivo para distinguirmos os pensamentos orientados para objetos de pensamentos descritivos seja experimentos de pensamento nos quais a descrição falha, mas a rota através da qual a pessoa está pensando no objeto permanece inalterada (idem).

Em outras palavras, se quisermos determinar a diferença entre pensamentos orientados para objetos e pensamentos descritivos, precisamos cavar um pouco mais fundo do que nos permite a metáfora dos arquivos mentais, uma vez que esta metáfora, na elaboração de Crane, quase que apenas transfere para um registro psíquico as dificuldades semânticas de se diferenciar os pensamentos em questão.

A busca pelo fundamento da distinção entre os pensamentos orientados para objetos e os pensamentos descritivos faz com que Azzouni resgate a definição da noção de acquaintance oferecida por Recanati. Ainda que esta noção tenha sido descartada quando se atinou à possibilidade de pensarmos singularmente objetos inexistentes, ou seja, objetos com os quais não desenvolveríamos nenhuma relação de acquaintance, sua definição pode auxiliar na especificação da fonte da diferença entre as duas maneiras de pensar consideradas. Afinal, a noção de acquaintance constitui o mais difundido ponto de partida na caracterização dos pensamentos singulares.

Para Recanati (2010, p. 152), as relações de acquaintance seriam relações epistemicamente recompensadoras, de modo que "pensar em um objeto direta ou não-descritivamente é nele pensar através desta relação. Neste caso, o que determina a referência - aquilo sobre o que se pensa - é a relação". Para Azzouni, apesar de esta definição indicar um bom caminho, ela demandaria um refinamento. Deste modo, ele sugere que abandonemos os adjetivos "direta" e "não-descritivamente" e descrevamos a relação epistemicamente recompensadora como "uma relação que pode ser explorada como um 'canal informacional' para o objeto em questão" (AZZOUNI, 2011, p. 53). 
Obviamente, à luz dos argumentos anteriores, Azzouni também sugere que abandonemos "a ideia de que tais canais informacionais devam nos conectar com objetos atuais — que eles devam ser relações" (idem).

Pois bem, se tais canais informacionais não devem ser relações, o que eles devem ser? Azzouni responde que

Podemos pensar neles como maneiras através das quais nós podemos manipular (e manipulamos) partes próximas do mundo para extrair informações - e que, às vezes, existe algo no remoto fim de uma cadeia causal que originou nossa manipulação do mundo, e, às vezes, não há nada. Portanto, assim como posso utilizar canais informacionais para descobrir coisas sobre o planeta Saturno, também posso utilizar canais informacionais para descobrir coisas sobre Mickey Mouse. Esses canais podem ser perceptuais, é claro (e, correspondentemente, podem ser alucinatórios); mas também podem envolver testemunhos ou instrumentação científica, ou a exploração inteligente de traços que os objetos fizeram no mundo (idem).

\section{E acrescenta que:}

Não deveríamos pensar nos canais informacionais de forma tão restrita; na verdade, não deveríamos pensar neles como canais informacionais em absoluto. Ao invés disso, deveríamos pensar neles como rotas percebidas para objetos que alguém pode ou não ser capaz de explorar. Se isto está correto, então o simples fato de que o nome de alguém encontra-se em domínio público é suficiente para criar a impressão de um 'canal informacional' para a pessoa nomeada. Pois este nome não possui nenhuma propriedade externa que indique como ele se refere ao seu referente. Logo (intuitivamente), seu papel como objeto social é aquilo que possibilita sua referência - que outras pessoas o usem para se referir ao seu referente. Quando utilizamos um nome em domínio público, por conseguinte, pensamos involuntariamente de maneira direcionada para objetos; um pensamento descritivo não é possível (ibid., p. 59).

De posse desta caracterização, arrisca-se uma determinação da diferença entre os pensamentos orientados para objetos e os pensamentos descritivos:

Se um ou outro canal informacional é ele mesmo fundamental para o pensamento, então o pensamento é orientado para objeto. Se as descrições (do canal informacional) são elas mesmas centrais, então o pensamento é descritivo. A distinção, então, não é entre duas diferentes espécies de arquivos mentais, como as sugestões anteriores afirmavam, a distinção se dá na maneira como as descrições são usadas pelo indivíduo: se o indivíduo detém-se atentamente nas descrições elas mesmas, ou se ele se detém nos canais informacionais aos quais as descrições (parcialmente) se referem. A distinção entre 
orientado para objeto e descritivo, como estou sugerindo, é uma distinção entre um foco no conteúdo de uma descrição por intermédio desta descrição em oposição a um foco no conteúdo de uma descrição independentemente desta descrição (ibid., p. 54).

Estamos cada vez mais perto de compreender a razão pela qual Azzouni julga ser possível pensarmos singularmente os objetos matemáticos.

Em seu raciocínio, Azzouni afirma que a mera presença de um nome em domínio público é capaz de criar a impressão de um "canal informacional" para o ser nomeado. Desta hipótese, ele deduz que, ao utilizarmos um nome, pensamos involuntariamente de maneira direcionada para objetos, pois o emprego do nome interditaria a rota para o desenvolvimento de um pensamento descritivo. Um pouco adiante, Azzouni destaca que os diagnósticos de pensamentos descritivos quase sempre podem ser modificados para pensamentos orientados para objetos, ainda que o inverso não proceda. Isto implica na tese de acordo com a qual "a fenomenologia dos pensamentos singulares mostra que eles são bastante comuns, e que (correspondentemente) pensamentos completamente gerais parecem mais raros" (ibid., p. 47). E é desta fenomenologia dos pensamentos singulares que surgem duas hipóteses.

A primeira diz respeito ao instrumentalismo semântico de Kaplan. Se esta teoria defende que basta a utilização de um nome para desenvolvermos pensamentos singulares acerca do objeto nomeado, Azzouni pensa que ela está correta. Mas com uma condição: que o nome em questão já esteja em domínio público. A possibilidade de um indivíduo inventar um nome para uso privado seria insuficiente para o desenvolvimento de pensamentos orientados para objetos.

A segunda diz respeito ao caso matemático. Azzouni afirma (ibid., p. 60) que "o mero uso de um nome numérico em domínio público é suficiente para ativar pensamentos direcionados para objetos mesmo sem um (genuíno) canal informacional". Isto é, o fato de os objetos matemáticos serem publicamente nomeados seria suficiente para configurar uma relação epistemicamente recompensadora através da qual podemos manipulá-los com vistas à elaboração de novas informações, independentemente das descrições utilizadas. Diz Azzouni (idem) que "podemos considerar isso como o tímpano do mecanismo 
dos canais informacionais que desencadeia o pensamento direcionado a objetos".

Após conjecturar sobre o caso matemático, Azzouni afirma (idem) que "podemos, se quisermos, tratar da mesma forma os bem sucedidos pensamentos orientados para objetos em relação ao inexistente. Apenas o nome, “Mickey Mouse”, em geral, é suficiente para desencadear pensamentos orientados para objetos". E não é uma simples coincidência ele se valer do caso matemático como uma porta para o caso dos objetos inexistentes. Pois, se até agora acompanhamos a argumentação de Azzouni em seu artigo sobre a natureza dos pensamentos singulares - seu papel cognitivo e sua fundamentação em canais informacionais -, não seria incorreto dizer que as reflexões presentes neste artigo são anunciadas no livro Talking About Nothing e complementadas pelo ensaio "Mathematical Fictions". Neste ensaio, Azzouni analisa algumas ilusões cognitivas nas quais nos encontraríamos enredados. Particularmente interessante para a teoria cujos traços esboçamos é a ilusão de que a atinência de nosso pensamento deve nos conectar com um objeto existente. Para Azzouni (2015, p. 68), "nossa matemática é cheia de ficções do mesmo tipo que aparecem nas histórias que narramos"; o problema, continua, é julgarmos que as ficções servem apenas para nos entreter. A reflexão de Azzouni sobre os pensamentos singulares lança-nos em seu nominalismo, a tese de acordo com a qual "nenhum termo matemático refere" (idem). O desenvolvimento destes traços de sua teoria, porém, nos levaria longe demais.

\section{Questões e perspectivas}

É importante compreendermos que a mera afirmação de nossa capacidade de pensar singularmente objetos matemáticos pressupõe uma série de

\footnotetext{
7 É interessante a utilização do substantivo "tímpano" (ou "enjunta" — a palavra utilizada por Azzouni é "spandrel"), pois este termo, originalmente arquitetônico, designa um espaço triangular geralmente encontrado em pares, entre o topo de um arco e uma moldura retangular, um espaço cujas possibilidades artísticas demoraram a ser percebidas e exploradas pelos artistas, mas que, uma vez percebidas, ampliaram e complexificaram a beleza das construções em que estavam inseridos. Azzouni parece sugerir que o mesmo acontece com os objetos matemáticos. Isto é, que os pensamentos orientados para objetos relacionados com os objetos matemáticos constituiriam um espaço teórico que sempre esteve presente, mas apenas quando demos por sua presença começamos a explorar suas mais diversas possibilidades.
} 
respostas para uma série de questões que aqui não encontraram seu desenvolvimento. Em primeiro lugar, a existência de pensamentos singulares não é consensual no interior da tradição filosófica, fato que implicaria em uma defesa inicial da própria existência de tais pensamentos. Em segundo lugar, é possível admitir a existência de pensamentos singulares sem que, com isso, admita-se a possibilidade de assim pensarmos quaisquer objetos com os quais não estabeleçamos uma relação causal, fato que implicaria na defesa de um caráter contingente da relação causal em nosso processo de pensamento. Em terceiro lugar, é possível reconhecer que, em nosso pensamento, nós nos relacionamos singularmente com "objetos ficcionais" ou até mesmo com "objetos alucinatórios", sem que com isso queiramos nos comprometer com a existência de pensamentos singulares sobre objetos matemáticos, fato que demandaria uma caracterização mais aguda da mecânica conceitual envolvida na possibilidade de assim pensarmos os objetos matemáticos. Em verdade, as desinteligências no reino dos pensamentos singulares multiplicam-se a cada tópico destacado.

As teorias de Azzouni e Davies oferecem distintas portas de entrada não apenas para o estudo dos pensamentos singulares como para o estudo sobre pensamentos singulares sobre objetos matemáticos. Por um lado, Davies sustenta que os arquivos mentais constituem o fundamento dos pensamentos singulares, que os pensamentos singulares são caracterizados à luz de seu conteúdo e que dependem da existência de seu objeto. Em resumo, ele investiga de que maneira podemos ampliar o conjunto dos objetos singularmente pensados, de modo a nele incluirmos os objetos matemáticos, respeitando nossas intuições habituais sobre os termos matemáticos. Por outro lado, Azzouni sustenta que os pensamentos singulares deveriam, à luz de seu comportamento cognitivo, ser caracterizados como uma maneira de pensar, o que faz com que sua designação seja modificada e eles passem a ser denominados como pensamentos orientados para objetos. Este posicionamento implica que nossos pensamentos não dependem da existência do objeto, uma vez que podemos pensar em diversos objetos inexistentes. $\mathrm{O}$ caso dos objetos ficcionais (tais como "Mickey Mouse") é mais discutido no artigo que orientou a exposição, 
mas indiquei que, no entender de Azzouni, os objetos matemáticos possuem o mesmo estatuto metafísico que os objetos ficcionais. Para onde vamos a partir daqui?

Uma maneira de concluirmos esta introdução ao estudo dos pensamentos singulares sobre objetos matemáticos consiste em decidirmo-nos por uma das alternativas apresentadas, isto é, podemos argumentar que a análise de Davies mostra-se mais promissora do que a de Azzouni, ou vice-versa. Por outro lado, podemos nos exercitar dialeticamente na elaboração de um argumento capaz de abranger as teorias de Davies e de Azzouni. Naturalmente, também podemos argumentar que ambas as teorias não acertam o alvo em questão, seja este uma caracterização mais específica dos pensamentos singulares sobre objetos matemáticos. No entanto, não gostaria de seguir por nenhum desses caminhos; gostaria apenas de destacar algumas questões suscitadas pelo estudo que encontrou neste artigo um de seus retratos.

O fato de Davies incorporar em sua proposta o quadro teórico desenhado por Jeshion direciona nosso olhar para a teoria por ela desenvolvida. Com efeito, apesar de Jeshion prometer, aqui e ali, um estudo mais detalhado para o caso dos pensamentos singulares acerca de objetos matemáticos, ${ }^{8} \mathrm{e}$ apesar de ela ter escrito um artigo inteiramente dedicado à noção de "intuição matemática", ${ }^{9}$ não há nenhum desenvolvimento de seu Cognitivismo nesta direção. A análise dos pensamentos singulares sobre objetos matemáticos de uma perspectiva cognitivista seria bem-vinda no conjunto de estudos sobre a natureza de tais pensamentos.

Do mesmo modo, a advertência de Recanati lança uma sombra sobre a caracterização dos arquivos mentais efetuada por Davies. ${ }^{10}$ Aparentemente, sua caracterização dos arquivos mentais apenas conecta algumas críticas efetuadas por Rachel Goodman com a configuração conceitual de Recanati. O problema, aqui, consiste em saber se haveria algum denominador comum capaz de reunir os defensores da teoria dos arquivos mentais (tais como Recanati, Jeshion e Crane), ou se, como afirma Recanati, cada pessoa efetivamente

\footnotetext{
${ }^{8}$ Cf. Jeshion 2002, p. 56-57; Jeshion 2004, p. 607-610.

${ }^{9}$ Cf. Jeshion 2014b.

${ }^{10}$ Cf. Recanati, 2014, p. 165.
} 
elabora a metáfora dos arquivos mentais à sua maneira. Na recém-publicada coletânea Singular Thought and Mental Files, Murez, Smortchkova e Strickland analisam o que eles consideram a mais ambiciosa versão da teoria dos arquivos mentais vinculada aos pensamentos singulares. ${ }^{11}$ Seu trabalho, porém, tem por objetivo avaliar criticamente o modo pelo qual diversos filósofos teriam superestimado a noção de "arquivo" utilizada nas ciências cognitivas, desenvolvendo uma noção de arquivo mental que não encontraria sustentação nas pesquisas psicológicas (algo já indicado por Laura Schroeter em relação à "transparência" de um arquivo mental para o sujeito cognoscente). A investigação das propriedades consensuais dos arquivos mentais também seria bemvinda nos estudos dos pensamentos singulares.

Por sua vez, Azzouni, em sua teoria, claramente favorece o papel desempenhado pelos nomes próprios em relação aos demais termos singulares. Em verdade, à exceção dos nomes descritivos e indexicais, podemos dizer que praticamente todas pesquisas sobre os pensamentos singulares privilegiam ora os nomes próprios, ora os pronomes demonstrativos. Deste modo, podemos perguntar: haveria uma hierarquia entre os termos singulares? Isto é, seriam os nomes próprios mais fundamentais do que os pronomes demonstrativos ou vice-versa? Assim como Azzouni, Jeshion também concede uma primazia aos nomes próprios, ao passo que Recanati privilegia o papel dos pronomes demonstrativos. ${ }^{12}$ Recentemente, Imogen Dickie dedicou um longo ensaio à compreensão dos termos singulares em nossa linguagem natural a partir de sua teoria do "foco cognitivo". ${ }^{13}$

Ainda no início de seu artigo, Azzouni afirma ser uma questão delicada especificar qual seria a relação entre pensamento e linguagem — um diagnóstico que, por extensão, se aplicaria à relação entre pensamento singular e proposição singular. De fato, esta é uma questão bastante sútil. Por um lado, Elizabeth Spelke e Susan Hespos assinalam, a partir de seus experimentos, que as crianças nascem com um sistema independente da linguagem que as auxilia a pensar nos objetos; por outro lado, Lera Boroditsky e Guy Deutscher

\footnotetext{
${ }^{11}$ Cf. Murez, Smortchkova, and Strickland 2020.

${ }^{12}$ Cf. Jeshion 2009; Jeshion 2010c; Jeshion 2014; Recanati 2010; Recanati 2012

${ }^{13}$ Cf. Dickie 2020.
} 
assinalam que a linguagem é a responsável por moldar nossos pensamentos, cuja implicação mais imediata consiste na hipótese segundo a qual elaboramos pensamentos diferentes em diferentes línguas. ${ }^{14} \mathrm{~A}$ grandeza, a complexidade e a importância deste problema para os estudos sobre os pensamentos singulares é bastante perceptível.

Obviamente, muitos outros problemas poderiam ser destacados. Estas questões, porém, constituem o núcleo das pesquisas que procuram averiguar a fertilidade da seguinte hipótese: ao especificarmos os mecanismos favoráveis ao desenvolvimento de pensamentos singulares, particularmente no que diz respeito ao caso dos objetos matemáticos, esquadrinhamos o funcionamento psico-semântico dos pensamentos singulares em seu contraste com os pensamentos descritivos. Contudo, estaríamos com isso estabelecendo uma espécie de pêndulo cognitivo do ser humano? Isto é, será que estaríamos destinados a pensar apenas de maneira descritiva ou de maneira singular? Não haveria aqui possibilidades ainda inexploradas? Conseguiríamos nos relacionar com os mais variados objetos de uma maneira que esteja para além das formas condensadas pelos pensamentos singulares e descritivos? Apesar de não possuir uma resposta para estas perguntas, elas ajudam-me a colocar em perspectiva todos os argumentos aqui estudados.

\section{Referências}

AZZOUNI, Jody. "Empty De Re Attitudes About Numbers". Philosophia Mathematica, v. 3, n. 17, 2009, p. 163-188.

Talking About Nothing: Numbers, Hallucinations, and Fictions. Oxford: Oxford University Press, 2010.

—. "Singular Thoughts (Objects-Directed Thoughts)". Proceedings of the Aristotelian Society Supplementary Volume, v. 85, 2011, p. 45-61. "Mathematical Fictions". In: SUKLA, Ananta (ed.). Fiction and Art: explorations in contemporary philosophy. London: Bloomsbury, 2015, p. 63-77.

BACH, Kent. Thought and Reference. Oxford: Clarendon Press, 1987.

${ }^{14}$ Cf. Hespos, and Spelke 2004; Boroditsky 2001; Deutscher 2010. 
- "Getting a Thing Into a Thought". In: JESHION, Robin (ed.). New Essays on Singular Thought. Oxford: Oxford University Press, 2010, p. 39-63.

BORODITSKY, Lera. "Does Language Shape Thought? Mandarin and English Speakers' Conceptions of Time”. Cognitive Psychology, v. 43, 2001, p. 122.

CUNHA, Celso, e CINTRA, Lindley. Nova Gramática do Português Contemporâneo. Rio de Janeiro: Editora Lexikon, 2008.

CRANE, Tim. "The Singularity of Singular Thought". Proceedings of the Aristotelian Society Supplementary Volume, v. 85, 2011, p. 21-43.

. The Objects of Thought. Oxford: Oxford University Press, 2013.

DAVIES, James E. "Towards a theory of singular thought about abstract mathematical objects”. Synthese, v. 196, n. 10, 2019, p. 1-24.

DEUTSCHER, Guy. Through the language glass: why does the world looks different in other languages. New York: Metropolitan Books, 2010.

DICKIE, Imogen. "Understanding Singular Terms". Proceedings of the Aristotelian Society Supplementary Volume, v. 94, 2020, p. 19-55.

GOODMAN, Rachel. "Against the mental files conception of singular thought". Review of Philosophy and Psychology, v. 7, 2016, p. 1-25.

HESPOS, Susan, e SPELKE, Elizabeth. "Conceptual precursors to language". Nature, v. 430, 2004, p. 453-456.

JESHION, Robin. “Acquaintanceless De Re Belief”. In: CAMPBELL, O'ROURKE, e SHIER (eds.). Meaning and Truth. New York: Seven Bridges Press, 2002, p. 53-74.

. "Descriptive Descriptive Names". In: BEZUIDENHOUT, Anne, e REIMER, Marga (eds.). Descriptions and Beyond, Oxford: Clarendon Press, 2004, p. 591-612.

- "The Significance of Names". Mind and Language, v. 24, n. 4, 2009, p. 370-403. sity Press, 2010a.

(ed.). New Essays on Singular Thought. Oxford: Oxford Univer"Introduction to New Essays on Singular Thought". In: JESHION, Robin (ed.). New Essays on Singular Thought. Oxford: Oxford University Press, 2010b, p. 1-35. 
and Cingular Thought: Acquaintance, Semantic Instrumentalism, Thought. Oxford: Oxford University Press, 2010c, p. 105-140.

- "Two Dogmas of Russellianism". In: GARCÍA-CARPINTERO, Manuel, and MARTÍ, Genoveva (eds.). Empty Representations: Reference and Non-Existence. Oxford: Oxford University Press, 2014a, p. 67-90.

327-349.

. "Intuiting the Infinite". Philosophical Studies, v. 171, 2014b, p.

McDOWELL, John. Meaning, Knowledge, and Reality. Cambridge: Harvard University Press, 1998.

MUREZ, SMORTCHKOVA, e STRICKLAND. "The Mental Files Theory of Singular Thought”. In: GOODMAN, GENONE, e KROLL (eds.). Singular Thought and Mental Files. Oxford: Oxford University Press, 2020, 107-142.

RECANATI, François. "Singular Thought: In Defense of Acquaintance". In: JESHION, Robin (ed.). New Essays on Singular Thought. Oxford: Oxford University Press, 2010, p. 141-189.

Mental Files. Oxford: Oxford University Press, 2012.

. "Empty Singular Terms in the Mental File Framework" . In: GARCÍA-CARPINTERO, Manuel, and MARTÍ, Genoveva (eds.). Empty Representations: Reference and Non-Existence. Oxford: Oxford University Press, 2014, p. 165-182.

Mental Files in Flux. Oxford: Oxford University Press, 2016.

SCHROETER, Laura. "The Illusion of Transparency". Australasian Journal of Philosophy. v. 85, n. 4, 2007, p. 597-618. 